\title{
A Case Report of Chronic Expanding Hematoma of the Left Erector Spinae Muscle After Stereotactic Body Radiotherapy for Renal Cell Carcinoma
}

\section{Yojiro Ishikawa ( $\sim$ y02614111@yahoo.co.jp )}

Tohoku University Hospital Department of Radiation Oncology: Tohoku Daigaku Byoin Hoshasen Chiryoka https://orcid.org/0000-0002-4613-0332

\section{Rei Umezawa}

Tohoku University Hospital Department of Radiation Oncology: Tohoku Daigaku Byoin Hoshasen Chiryoka

\section{Takaya Yamamoto}

Tohoku University Hospital Department of Diagnostic Radiology: Tohoku Daigaku Byoin Hoshasen Shindanka

\section{Noriyoshi Takahashi}

Tohoku University Hospital Department of Radiation Oncology: Tohoku Daigaku Byoin Hoshasen Chiryoka

\section{Kazuya Takeda}

Tohoku University Hospital Department of Radiation Oncology: Tohoku Daigaku Byoin Hoshasen Chiryoka

\section{Yu Suzuki}

Tohoku University Hospital Department of Radiation Oncology: Tohoku Daigaku Byoin Hoshasen Chiryoka

\section{Keiichi Jingu}

Tohoku University Hospital Department of Radiation Oncology: Tohoku Daigaku Byoin Hoshasen Chiryoka

\section{Case report}

Keywords: chronic expanding hematomas, SBRT, renal cell carcinoma

Posted Date: November 11th, 2021

DOI: https://doi.org/10.21203/rs.3.rs-1033024/v1

License: (c) (i) This work is licensed under a Creative Commons Attribution 4.0 International License. Read Full License 


\section{Abstract}

Background: Hematomas that slowly increase in size for over a period of more than one month after the initial hemorrhage are referred to as chronic expanding hematoma (CEH). We report a case of CEH of left erector spinae muscle after stereotactic body radiotherapy (SBRT) for renal cell carcinoma (RCC).

Case presentation: A 74-year-old Japanese male complained of back pain. There was no history of surgery or trauma of his back. He received SBRT for RCC of left kidney of seven years ago. Computed tomography (CT) revealed the left erector spinae muscle was swollen compared to the contralateral side at the third lumbar level. Ultrasonography showed a tumor of $30 \mathrm{~mm}$ in size without blood flow in left paraspinal muscle. Positron emission tomography-CT revealed uptake in the left paraspinal muscle. Pathological examination showed radiation-induced $\mathrm{CEH}$. We performed conservative therapy with medication alone because the tumor had been gradually growing. One year after starting observation, the patient died due to subdural hemorrhage after a fall and progression of renal failure.

Discussion and conclusions: Because this study was a case study, it is difficult to definite the CEH after SBRT. Since SBRT has recently been increasing, SBRT-induced CEH is considered to be an important complication.

\section{Background}

Hematoma that slowly increase in size for over a period of more than one month after the initial hemorrhage are referred to as chronic expanding hematoma (CEH). CEH are related to previous surgery or trauma [1]. There have been reports of the $\mathrm{CEH}$ in the brain after treatment with a gamma knife [2][3]; however, there has been no report about CEH in the trunk after radiotherapy. We report have a case of CEH of the left erector spinae muscle after stereotactic body radiotherapy (SBRT) for renal cell carcinoma (RCC).

\section{Case Report}

A 74-year-old Japanese male complained of back pain. There was no history of drinking or smoking. The medical history of the patient was dialysis due to nephrotic syndrome, operation of abdominal aortic aneurysm, coronary stenting, pacemaker implantation and right renal cell carcinoma (RCC). He received SBRT for the left kidney of 70 Gy in 10 fractions seven years ago (Fig. 1). He did not have a history of medical or surgical therapy for tuberculosis. His medications were Bayaspirin and Clopitogrel Salufate. His family history included duodenal cancer in his father.

Computed tomography (CT) revealed that the left erector spinae muscle was swollen compared to the contralateral side at the third lumbar level (Fig. 2). The lesion appeared to have a nodular structure including high and low attenuation areas. Retrospectively, it had been clarified five years ago, but the change was gradual (Fig. 3). Ultrasonography showed a tumor of $30 \mathrm{~mm}$ in size without blood flow in left paraspinal muscle (Fig. 4). Magnetic resonance imaging was not performed because he was a 
pacemaker patient. Positron emission tomography-CT (PET-CT) revealed uptake of 18F-2-fluoro-2-deoxyD-glucose (FDG) in the left paraspinal muscle (maximum standardized uptake value of 2.8) (Fig. 5). We therefore suspected a malignant tumor, a benign tumor such as schwannoma, vascular malformations or chronic expanding hematoma.

Pathological examination of biopsy specimens from the lesion of the left erector spinae muscle showed bleeding and fibrine precipitation. In addition, atrophy and glassy fibrosis of the straited muscle due to radiotherapy were observed. The clinical diagnosis was radiation-induced $\mathrm{CEH}$.

We performed conservative therapy with medication alone because the tumor had been gradually growing. One year after starting observation, the patient died due to subdural hemorrhage after a fall and progression of renal failure.

\section{Discussion}

CEH is related to a history of surgery or trauma. In addition, $\mathrm{CEH}$ in the chest occur in patients with a history of treatment for tuberculosis $[4,5]$. The durations between these previous episodes and first diagnosis of CEH can vary from one month to decades [6]. CEH can result from stimulation of blood and its degradation products, leading to repeated exudation or bleeding from the capillaries of granulation tissue. The factors that trigger this behavior in some hematomas are unclear[7]. Anticoagulant therapy was shown to be associated with the incidence of $\mathrm{CEH}$. Treatment of $\mathrm{CEH}$ is total resection. However, complete resection has been reportedly difficult due to the presence of fibrous adhesions [8].

Of the 133 cases found in the present review (Table 1), 94 (71\%) of the cases were in males and $39(29 \%)$ of the cases were in females. The median age of the patients was 65 years (range of 8 - 89 years). The reported clinical latent periods ranged widely from 1 month to 660 months (median period of 252 months). The most common lesion site was the thorax including the chest wall of $59(44.4 \%)$ of the patients. Two patients $(1.5 \%)$ and 36 patients $(27.0 \%)$ patients had lesions in the upper and lower extremities, respectively, and 13 patients $(9.7 \%)$ and 16 patients $(12.0 \%)$ patients had lesions in the abdomen and pelvis, respectively. Forty patients $(30.0 \%)$ and 46 patients $(36.8 \%)$ had antecedent episodes of trauma and surgery, respectively, 7 patients (5.2\%) had undergone anticoagulant therapy, and 5 patients (3.8\%) were dialysis patients. The most common therapy for $\mathrm{CEH}$ was total resection; however, 6 patients (4.5\%) patients did not undergo resection. In 6 patients (4.5\%) patients, CEH was the cause of death. 
Table 1

Review of the 133 cases with chronic expanding hematoma

\begin{tabular}{|c|c|}
\hline & $N=133$ \\
\hline \multicolumn{2}{|l|}{ Sex } \\
\hline Male & $94(71 \%)$ \\
\hline Female & $39(29 \%)$ \\
\hline \multicolumn{2}{|l|}{ Age (years) } \\
\hline Median & $65(48-89)$ \\
\hline \multicolumn{2}{|l|}{ Location } \\
\hline Upper extremities & $2(1.5 \%)$ \\
\hline Lower extremities & $36(27.1 \%)$ \\
\hline Thorax & $59(44.4 \%)$ \\
\hline Abdomen & $13(9.7 \%)$ \\
\hline Pelvis & $16(12.0 \%)$ \\
\hline Head and neck & $3(2.3 \%)$ \\
\hline Other & $4(3.0 \%)$ \\
\hline \multicolumn{2}{|c|}{ Antecedent episode } \\
\hline Trauma & $40(30.0 \%)$ \\
\hline Surgery & $49(36.8 \%)$ \\
\hline Tuberculosis & $32(24.1 \%)$ \\
\hline Radiation therapy & $3(2.3 \%)$ \\
\hline Other & $2(1.5 \%)$ \\
\hline \multicolumn{2}{|c|}{ Range from antecedent episode (months) } \\
\hline Median & $252(1-660)$ \\
\hline \multicolumn{2}{|l|}{ Treatment } \\
\hline Surgery & $115(86.4 \%)$ \\
\hline Observation & $6(4.5 \%)$ \\
\hline Embolization & $15(11.3 \%)$ \\
\hline Unknow & $11(8.27 \%)$ \\
\hline
\end{tabular}


Our review showed that 3 cases $(2.2 \%)$ had a history of radiotherapy after surgery. In 2 cases with a history of radiotherapy, the irradiation area and dose were not clear. Sakamoto et al. reported that CEH occurred in the foot after an operation with adjuvant radiotherapy (84Gy) [9]. There have been reports of $\mathrm{CEH}$ in the brain after treatment with gamma knife for cerebral arteriovenous malformations [2][3]. However, there has been no report about chronic CEH after SBRT. This is the first report of CEH after SBRT.

Haemodialysis (HD) patients are at an increased risk of bleeding because of uraemic bleeding tendency and systemic anticoagulation caused by intermittent heparinization [10]. Therefore, HD might be associated with the incidence of $\mathrm{CEH}$. CEH occurred in some patients undergoing HD. Our patient had a medical history of HD due to nephrotic syndrome.

\section{Conclusions}

Because this study was a case study, it is difficult to definite the CEH after SBRT. Although such a slowly expanding, located, and modestly symptomatic CEH may not have a great impact in clinical; however, it is possible that $\mathrm{CEH}$ occurs in some patients after SBRT. Since SBRT has recently been increasing, SBRTinduced $\mathrm{CEH}$ is considered to be an important complication.

\section{Abbreviations}

CT: Computed tomography

HD: Haemodialysis

PET-CT: Positron emission tomography-CT

RCC: renal cell carcinoma

\section{Declarations}

\section{Ethics approval and consent to participate}

All procedures performed in studies involving human participants were in accordance with the ethical standards of the institutional research committee. For this type of study, formal consent is not required.

\section{Consent for publication}

Written informed consent was obtained from the patient and patient next to kin for publication of this case report and any accompanying images. A copy of the written consent is available for review by Editor-in-Chief of this journal.

\section{Availability of data and materials}


The data include individual patient data, but the data are available from the corresponding authors upon reasonable request.

\section{Competing interests}

The authors declare that they have no competing interests.

\section{Funding}

This case report was not supported by any funding.

\section{Authors' Contributions}

All listed authors contributed to the original manuscript. $\mathrm{YI}$ is the main radiation oncologist of this case and wrote the manuscript draft. RU and KJ coordinated and completed the manuscript. TY, NT, KT and US supported radiation therapy management. All authors have read and approved the manuscript of this case report.

\section{Acknowledgements}

None

\section{References}

1. Labadie EL, Glover D (1976) Physiopathogenesis of subdural hematomas. Part 1: Histological and biochemical comparisons of subcutaneous hematoma in rats with subdural hematoma in man. Journal of neurosurgery 45:382-392. https://doi.org/10.3171/jns.1976.45.4.0382

2. Lee $\mathrm{C}-\mathrm{C}, \mathrm{Pan} \mathrm{DH}-\mathrm{C}, \mathrm{Ho}$ DM-T, et al (2011) Chronic encapsulated expanding hematoma after gamma knife stereotactic radiosurgery for cerebral arteriovenous malformation. Clinical neurology and neurosurgery 113:668-671. https://doi.org/10.1016/j.clineuro.2011.03.010

3. Kurita H, Sasaki T, Kawamoto S, et al (1996) Chronic encapsulated expanding hematoma in association with gamma knife stereotactic radiosurgery for a cerebral arteriovenous malformation. Case report. Journal of neurosurgery 84:874-878. https://doi.org/10.3171/jns.1996.84.5.0874

4. Kouritas VK, Roussakis AG, Soultanis K, Bellenis I (2011) Extrathoracic chronic heamatoma presenting as a chest wall tumor 2 years after a blunt thoracic injury. Journal of cardiothoracic surgery 6:156. https://doi.org/10.1186/1749-8090-6-156

5. Kuronuma K, Ootake S, Ikeda K, et al (2008) Chronic expanding hematoma in the chest. Internal medicine (Tokyo, Japan) 47:1411-1414. https://doi.org/10.2169/internalmedicine.47.0724

6. Nakano M, Kondoh T, Igarashi J, et al (2001) A case of chronic expanding hematoma in the tensor fascia lata. Dermatology online journal 7:6

7. Reid JD, Kommareddi S, Lankerani M, Park MC (1980) Chronic expanding hematomas. A clinicopathologic entity. JAMA 244:2441-2442 
8. Takanami I (2003) Successful treatment of huge chronic expanding hematoma after thoracoplasty. The Journal of thoracic and cardiovascular surgery 126:1202-1203. https://doi.org/10.1016/s00225223(03)00787-6

9. Sakamoto A, Okamoto T, Tsuboyama T, Matsuda S (2019) Chronic Expanding Hematoma in the Thigh: A Late Complication 32 Years After Treatment of Synovial Sarcoma: A Case Report. The American journal of case reports 20:1449-1453. https://doi.org/10.12659/AJCR.917855

10. Janssen MJ, van der Meulen J (1996) The bleeding risk in chronic haemodialysis: preventive strategies in high-risk patients. The Netherlands journal of medicine 48:198-207. https://doi.org/10.1016/0300-2977(96)00005-8

\section{Figures}

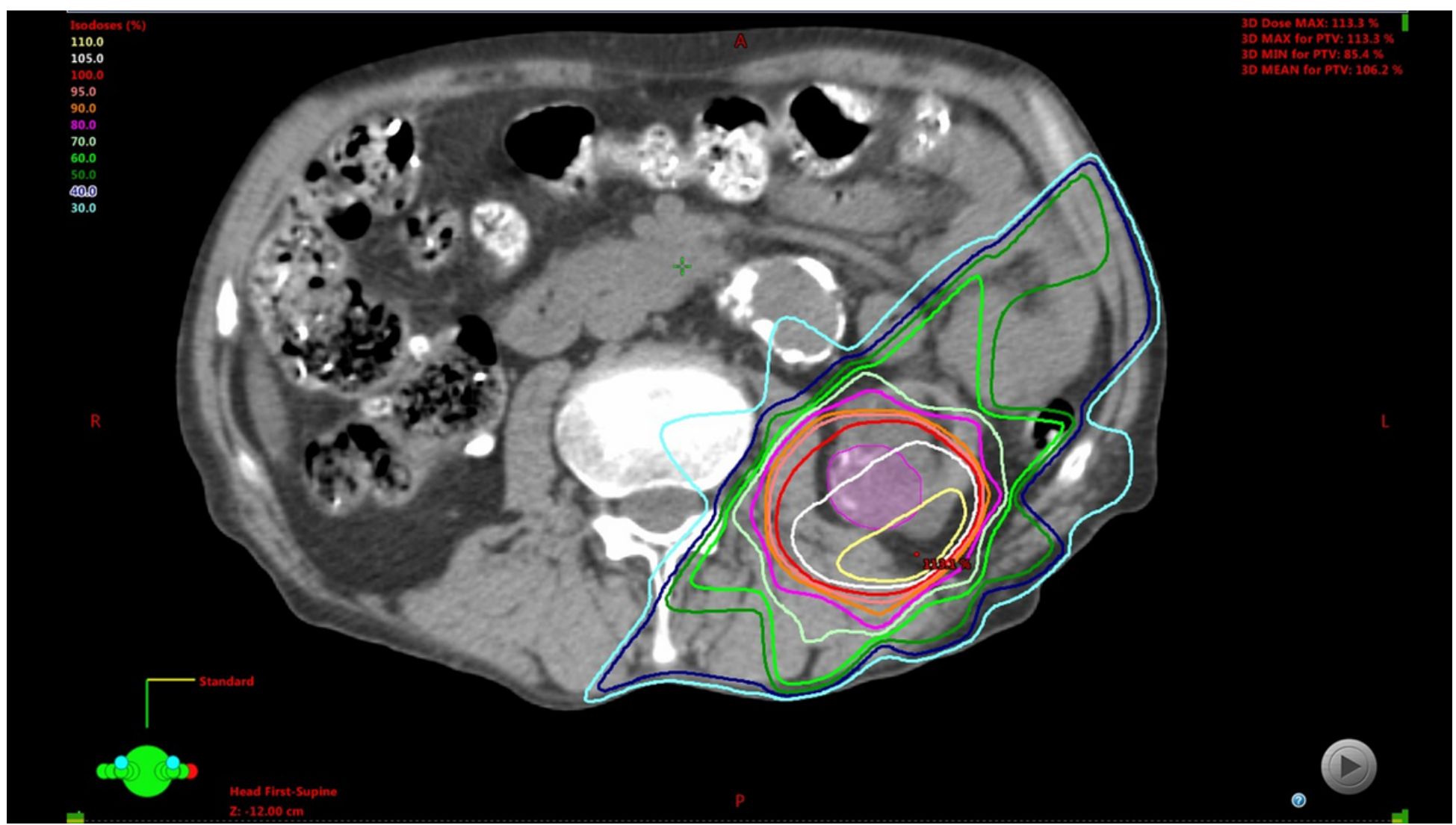

\section{Figure 1}

Axial image of dose distribution of stereotactic body radiotherapy (SBRT). SBRT was performed with 7 non-coplanar static $6 \mathrm{MV}$ X-ray beams to the lesion of the right kidney using daily cone-beam CT scan imaging before each fraction. The patient was prescribed $70 \mathrm{~Gy} / 10$ fractions for the isocenter. 


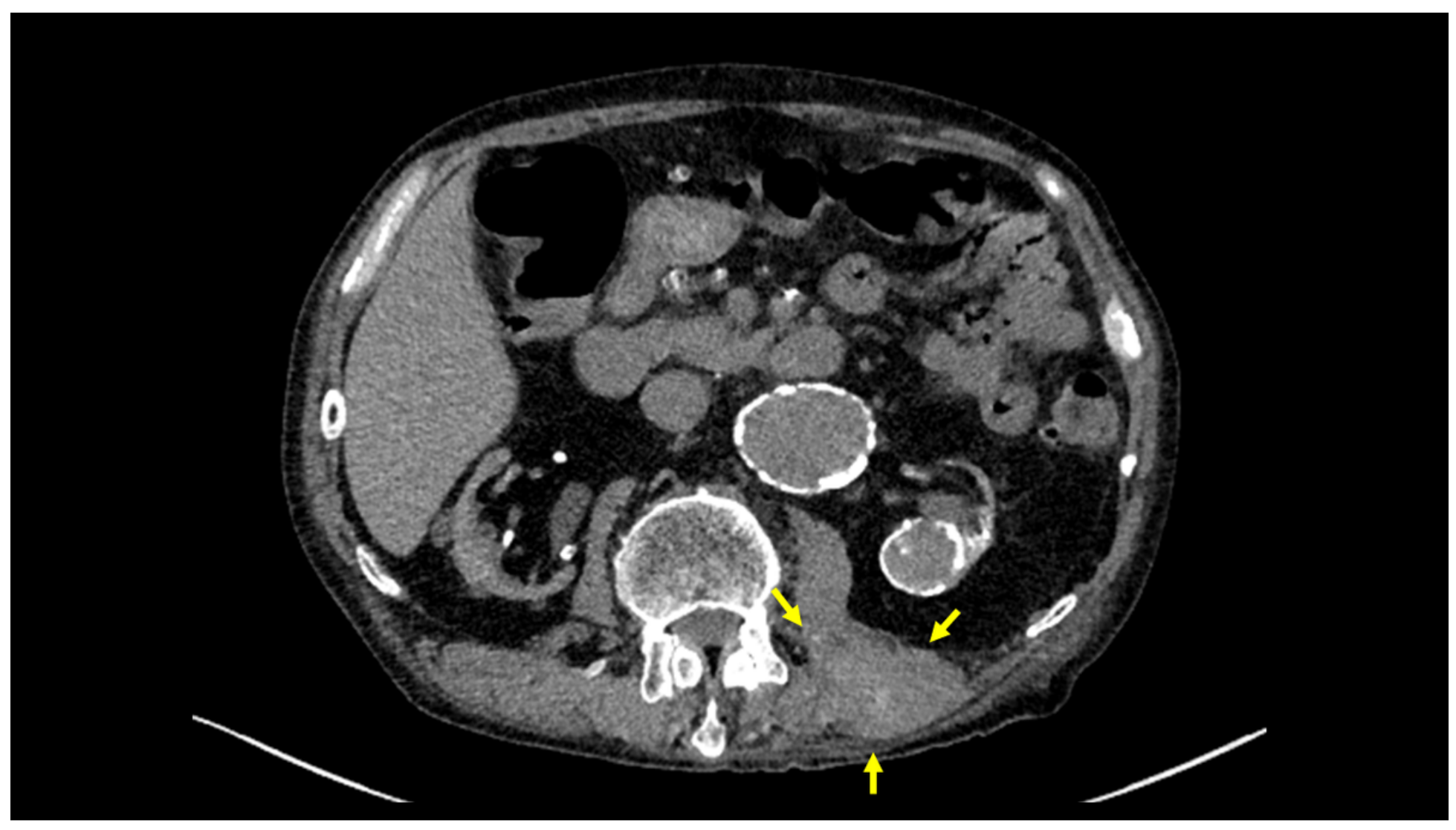

Figure 2

Axial enhanced computed tomography scan images showed a tumor that had spread to the left erector spinae muscle. The lesion appeared to have a nodular structure including high and low attenuation areas (yellow arrow). 


\section{Timeline for progression of chronic expanding hematoma}
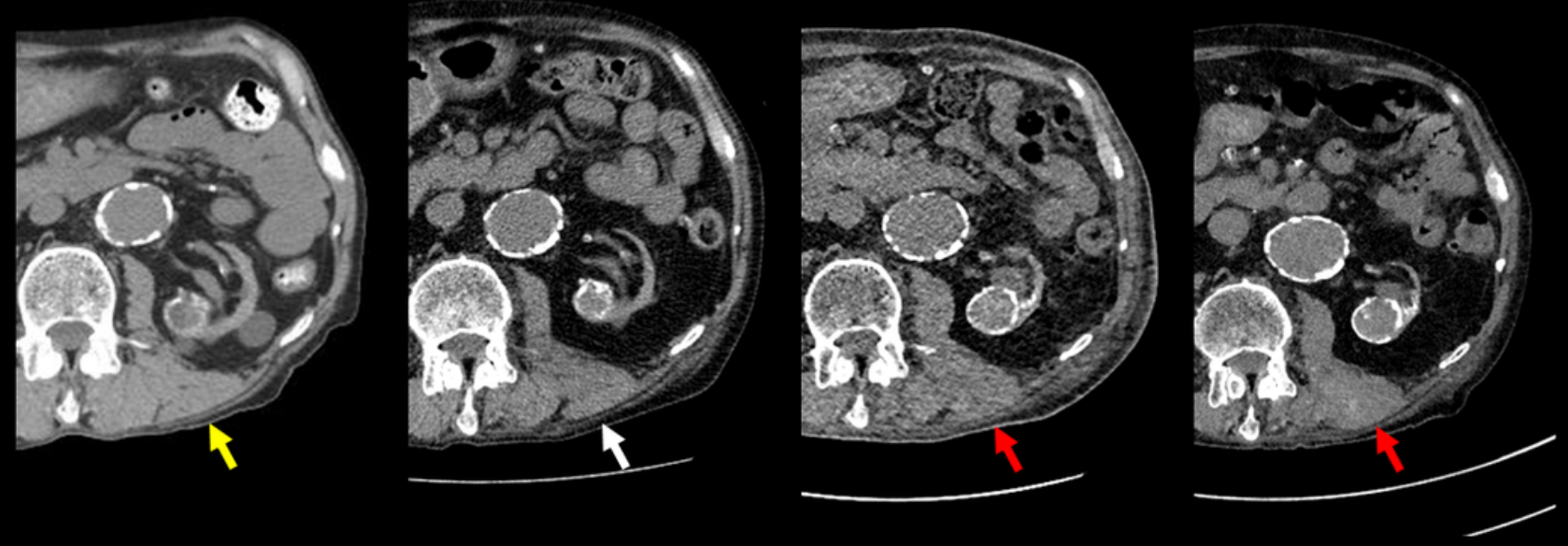

\section{Before RT}

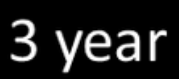

5 year

\section{7 year}

\section{Figure 3}

Timeline for progression of the chronic expanding hematoma on CT (yellow arrow). Before SBRT, the left erector spinae muscle was normal. The muscle gradually became atrophic 3 years after SBRT (white arrow). Finally, the muscle was swollen between 5 and 7 years after SBRT (red arrow). 


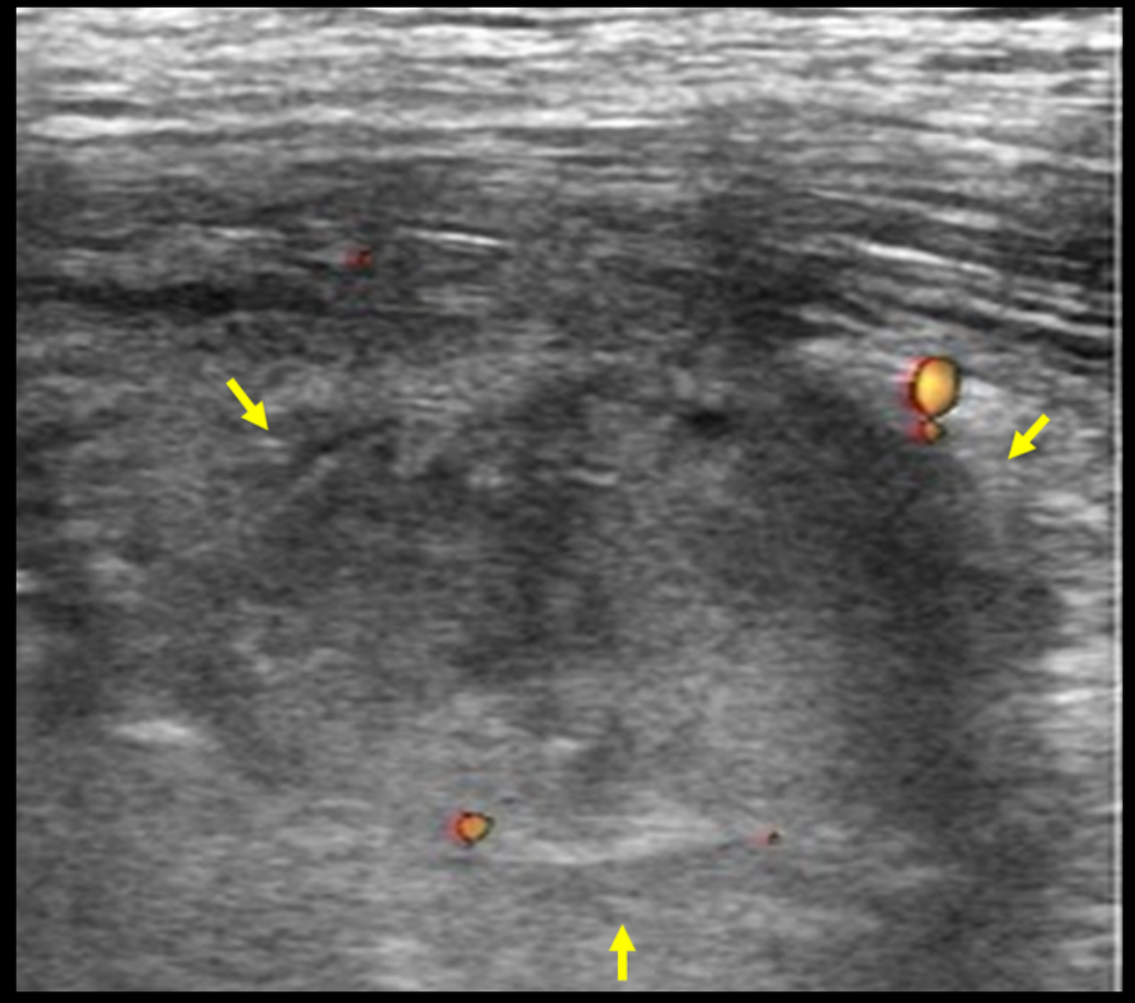

\section{Figure 4}

Ultrasonography of left erector spinae muscle showed an iso-hypo echoic tumor of $30 \mathrm{~mm}$ in size in the without blood flow (yellow arrow).

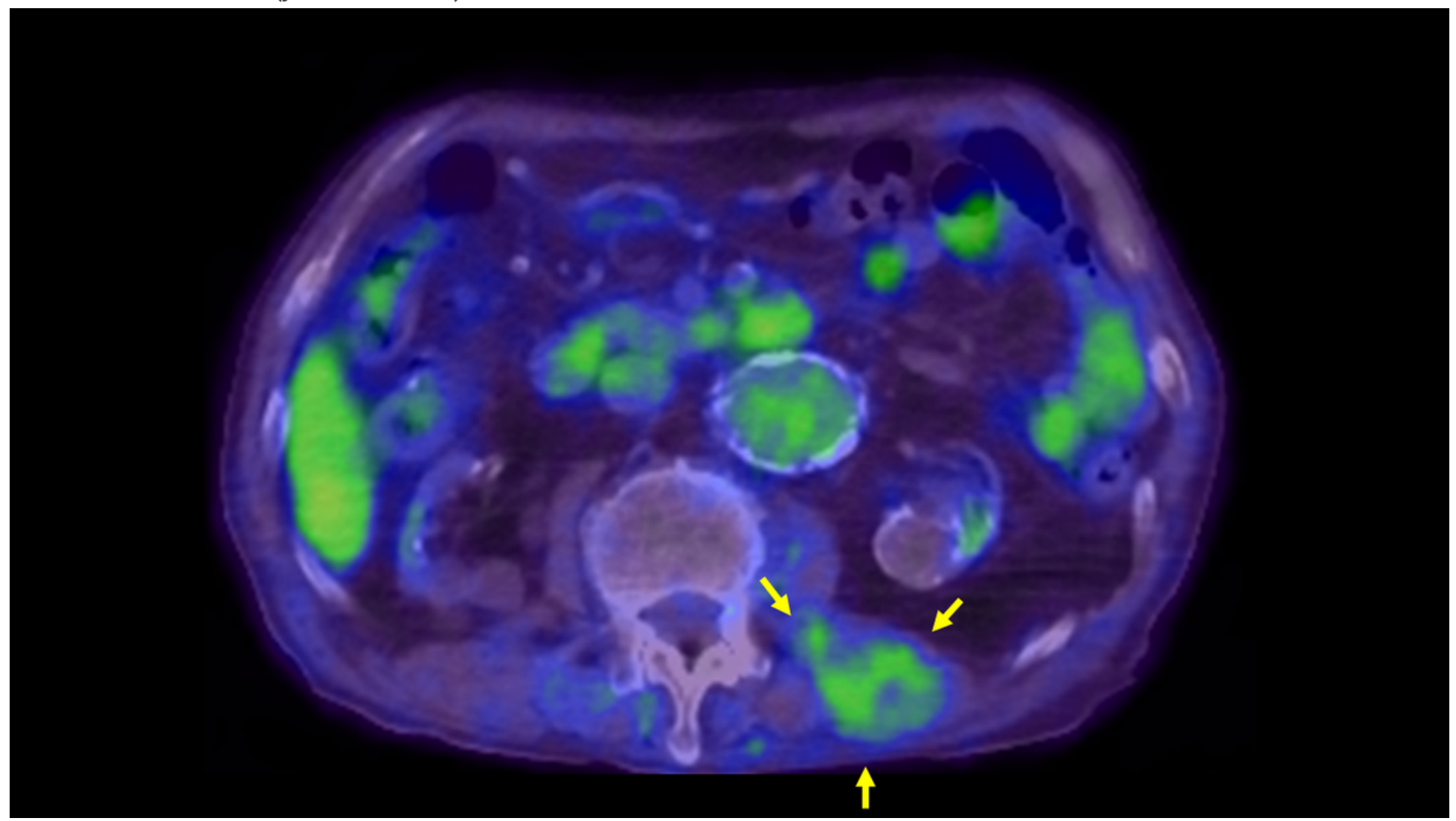


Figure 5

Positron emission tomography-CT showed uptake of 18F-2-fluoro-2-deoxy-D-glucose in the left erector spinae muscle with a maximum standardized uptake value (SUVmax) of 2.8 (yellow arrow). 